\title{
A ÉTICA DA INFORMAÇ̃̃O NOS PROGRAMAS DE PÓS-GRADUAÇÃO EM CIÊNCIA DA INFORMAÇ̃̃O NO BRASIL: UMA ANÁLISE ${ }^{1}$
}

\author{
Vinícius Cerva de Moraes ${ }^{2}$ \\ Universidade Federal do Rio Grande do Sul \\ v.cerva@hotmail.com \\ Jackson da Silva Medeiros ${ }^{3}$ \\ Universidade Federal do Rio Grande do Sul \\ jmedeiros@ufrgs.br
}

\begin{abstract}
Resumo
Objetiva verificar como está caracterizada a Ética da Informação nos Programas de Pós-Graduação em Ciência da Informação no Brasil por meio dos projetos de pesquisa, artigos e disciplinas dos Programas citados que possam estar abordando a área. Desenvolve, a fim de atingir estes objetivos, uma pesquisa básica, quantitativa e descritiva, sob a técnica de Análise de Conteúdo. Infere que há uma disparidade significativa com relação ao tópico da ética profissional do bibliotecário entre os indicadores de pesquisa e produção; que o papel da docente Isa Maria Freire nos assuntos que relacionam Ética da Informação com a Web é um destaque, e que Maria Nélida González Gómez, por mais que tenha sido vista sua participação só num projeto de pesquisa, ainda assim contribuiu com a criação de um livro em 2017 sobre Ética da Informação. Conclui que é interessante outro trabalho acadêmico sobre o mesmo assunto, aplicando, por exemplo, uma amostra e, além de coletar artigos, projetos e disciplinas, livros e capítulos de livros. Conclui, ainda, questionando a necessidade de haver uma "simetria" entre quantidade de projetos e artigos sobre um determinado assunto, bem como destaca a importância da Ética da Informação em função de desafios ético-informacionais propostos por tópicos como plágio e fake news.
\end{abstract}

Palavras-chave: Ética da Informação. Ciência da Informação. Programas de Pós-Graduação.

\section{INFORMATION ETHICS IN THE POST-GRADUATION PROGRAMS OF INFORMATION SCIENCE IN BRAZIL: AN ANALYSIS}

\begin{abstract}
It aims on understanding how Information Ethics is characterized in the Graduate Programs of Information Science in Brazil through research projects, articles and disciplines of the aforementioned Programs that can be approaching Information Ethics. It develops a basic, quantitative and descriptive research, using the technique of Content Analysis. It infers that it is occurring a significative disparity regarding the topic of the ethics of the librarian between the indicadors of research and production; that the role of Professor Isa Maria Freire in the subjects relating Information Ethics and the Web deserves an emphasis, and that Maria Nélida González Gómez, even though her participation was seen only in one research project, nevertheless contributed with the creation of a book in 2017 about Information Ethics. It concludes that it is interesting other academic work about Information Ethics, maybe gathering a sample of all the Programs and, this way, not being limited in analyzing disciplines, projects and articles, but also books and book chapters, for instance. It still concludes questioning the necessity of having a "symmetry" between the quantity of projects and articles about a certain subject, as well as highlighting the relevance of Information Ethics based on ethical-informational challenges presented by topics like plagiarism and fake news.
\end{abstract}

Keywords: Information Ethics; Information Science; Graduate Programs.

${ }^{1} \mathrm{O}$ presente trabalho foi realizado com apoio da Coordenação de Aperfeiçoamento de Pessoal de Nível Superior - Brasil (CAPES) - Código de Financiamento 001. Também conta com fomento do CNPq (Processo 431367/20167).

2 Graduado em Biblioteconomia pela Universidade Federal do Rio Grande do Sul

${ }^{3}$ Professor do Programa de Pós-Graduação em Ciência da Informação da Universidade Federal do Rio Grande do Sul.

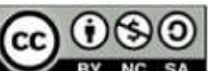

Esta obra está licenciada sob uma Licença Creative Commons Atribuição 4.0 Internacional (CC BY-NC-AS 4.0). LOGEION: Filosofia da informação, Rio de Janeiro, v. 6 n. 1, p.27-43, set.2019/fev. 2020 


\title{
1 INTRODUÇÃO
}

É constante, com o passar dos anos, uma preocupação ética por parte da sociedade com relação à conduta dos gestores de instituições, governantes, lideranças, etc. No entanto, questiona-se aqui se, para a maior parte desta sociedade, há também preocupação referente à conduta que atinge um nível mais sutil e que não se restringe às ações das instituições: o da informação. Refinando a pergunta a ser dirigida, podemos colocá-la no sentido de investigar os desafios éticos envolvendo produção, compartilhamento e uso de informação.

Temas problemáticos com relação à desinformação são assuntos de interesse da área que se volta a desafios ético-informacionais, a Ética da Informação (EI), e estão recebendo destaque para além do mundo acadêmico nos últimos anos. Froehlich $(2017$, p. 2) contextualiza essas questões da seguinte maneira:

\begin{abstract}
Qualquer discussão sobre Ética da Informação faz com que abordemos a ética da ignorância, desinformação, falta de informação e mentiras, não porque estas questões sejam propriamente éticas (elas se opõem a uma conduta ética), mas porque elas devem ser confrontadas e discutidas, visto que são desafios à Ética da Informação. É claro que o problema não é novo, mas as tecnologias de informação, como a internet, sua facilidade de acesso e seu rápido crescimento global têm engrandecido, consideravelmente, o problema.
\end{abstract}

Evidencia-se, então, preocupação ética relacionada à produção, compartilhamento e uso da informação, visto que alguém pode tomar uma decisão equivocada com base em sua incompetência informacional ou ainda frente à uma notícia que desconhece ser falsa, inclusive transmitindo-a. A Ética da Informação, enquanto área de estudo e preocupada com esse ciclo informacional, tem muito trabalho a ser feito diante de problemas debatidos na atualidade.

Outro tema de preocupação ético-informacional é o plágio. A atualidade (constante) do fenômeno pode ser exemplificada com a disciplina "Plágio no contexto da integridade científica", criada em 2017 para dois Programas na área de Ciência da Informação da USP: o Programa de Pós-Graduação em Ciência da Informação e o Programa de Pós-Graduação em Gestão da Informação ${ }^{4}$. Na justificativa para a criação da disciplina consta o seguinte:

\footnotetext{
No meio acadêmico tem aumentado a preocupação com ameaças à integridade científica, tais como a fabricação e falsificação de dados e resultados, bem como fraudes autorais individuais e coletivas, [...]. Neste contexto, instituições e agências de pesquisa brasileiras têm se posicionado demandando iniciativas preventivas e formativas relacionadas à integridade acadêmica em geral, mas com especial enfoque em relação ao plágio. ${ }^{5}$
}

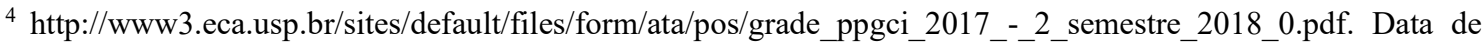
acesso: 28 dez. 2018.

${ }^{5}$ https://uspdigital.usp.br/janus/componente/catalogoDisciplinasInicial.jsf?action=3\&sgldis=CBD5943. Data de acesso: 28 dez. 2018.
} 
Os temas citados, dentre outros, trazem à baila e indicam a relevância de se abordar o caráter ético que envolve informação. Desafios como desinformação e plágio demandam respostas da academia.

Neste trabalho buscou-se discutir como desafios ético-informacionais estão sendo tratados dentro das universidades. Para isto, objetivou-se caracterizar a área da Ética da Informação nos Programas de Pós-Graduação em Ciência da Informação no Brasil. Isto se deu por meio de coleta e análise dos projetos de pesquisa, artigos e disciplinas que compõem/são produzidos nestes Programas, com abordagem de tópicos de interesse da EI, como desinformação, plágio, direito de acesso à informação e ética de profissionais da informação, entre outros.

Para esta apresentação, após a introdução, o capítulo 2 busca entender e realizar apropriações sobre Ética da Informação. No capítulo 3 são apresentados os tipos de materiais, bem como os procedimentos realizados para atingir os resultados. O capítulo 4 mostra os resultados e o capítulo 5 é responsável pela interpretação de dados, ou seja, as inferências. O capítulo 6 traz as considerações finais seguidas das referências.

\section{CONTEXTUALIZAÇÃO DA ÉTICA DA INFORMAÇÃO}

Para dar início a uma discussão sobre Ética da Informação (EI) é interessante buscar, inicialmente, uma conceituação. Capurro (2001, p. 1) distingue duas definições à área, uma que não envolve mudança de comportamento, pois não inclui nenhuma imposição normativa, e outra que envolve esta mudança, pois inclui aspectos normativos:

\footnotetext{
Ética da Informação como uma teoria descritiva explora as estruturas de poder que influenciam atitudes relacionadas à informação e tradições de diferentes culturas e épocas. Ética da Informação como uma teoria emancipatória desenvolve críticas de atitudes morais e tradições no campo da informação num nível individual e coletivo. Inclui aspectos normativos.
}

A teoria emancipatória pode explicar a criação de leis como a Lei de Acesso à Informação e o Marco Civil da Internet, por exemplo, pois é a ela que cabe uma avaliação de atitudes e tradições a partir da qual seria possível uma mudança no agir. Em paralelo à definição de Capurro, parece existir também uma importância dada exclusivamente à teoria emancipatória da EI.

Para Mathiesen (2015, p. 427), a Ética da Informação trataria somente do “[...] estudo de questões normativas relacionadas à criação, preservação, organização, acesso, apresentação e controle de informação". Isto parece se dar, provavelmente, em função da visão da autora de que alguns dos problemas da área científica como privacidade, vigilância, propriedade 
intelectual e acesso à informação só podem ser respondidos através da definição de políticas formais.

Capurro (2001, p. 1) segue caracterizando o campo científico, mostrando o que este explora (teoria descritiva) e avalia/julga (teoria emancipatória):

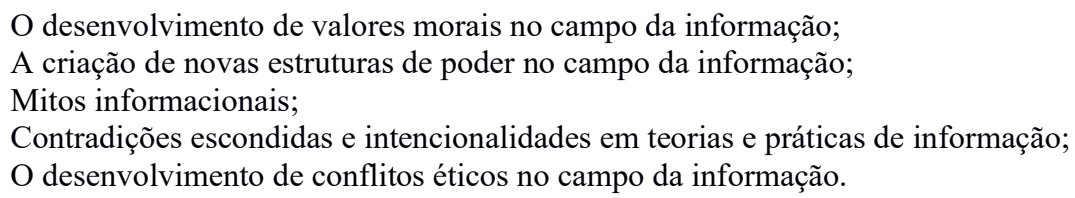

Com o avanço gradual das tecnologias digitais de informação, toma-se o interesse pelos estudos dos conflitos éticos no ambiente digital. Pesquisar informações na internet requer habilidade, pois nem tudo o que há de disponível possui credibilidade:

\footnotetext{
Em torno do acesso à informação, como recurso, existe hoje uma crescente literatura preocupada com a confiabilidade da informação disponibilizada pelos motores de busca, na internet, onde se analisam as condições de sua credibilidade (GONZÁLEZ DE GÓMEZ; CIANCONI, 2017, p. 40).
}

Enquadra-se neste problema da pesquisa eletrônica as fake news. Uma vez que se deseja estar diariamente informado, é preciso saber investigar as fontes de informação (discernir quais são confiáveis). Nas instituições de ensino, cumpre ao bibliotecário orientar estudantes quanto aos locais apropriados para a consulta de informação acadêmica na web, pois embora o fenômeno das fake news esteja vinculado, geralmente, a notícias, o conhecimento científico ainda pode ser distorcido por meio da desinformação, que é um correlato de fake news.

Dada uma breve introdução sobre Ética da Informação, dirigir-se-á, agora, à metodologia utilizada que propiciou os resultados de pesquisa.

\section{METODOLOGIA}

De caráter quantitativo, o trabalho buscou determinar a ocorrência de tópicos de interesse da Ética da Informação em artigos, disciplinas e projetos de pesquisa nos Programas de Pós-Graduação em Ciência da Informação no Brasil. Quanto ao objetivo, optou-se pela pesquisa descritiva. Não se pretendeu identificar razões para a ocorrência de quaisquer fenômenos, nem construir hipóteses para se obter uma maior familiaridade com o problema (GERHARDT; SILVEIRA, 2009), razão pela qual se escolheu o tipo de pesquisa, permitindo "conhecer e interpretar a realidade" (RUDIO, 1978, p. 55), bem como "observar fenômenos, procurando descrevê-los, classificá-los e interpretá-los" (RUDIO, 1978, p. 56).

O procedimento utilizado para realização das análises de pesquisas foi a Análise de Conteúdo. Conforme Laurence Bardin (2010), trata-se de "um conjunto de técnicas de análise 
das comunicações. [...] um único instrumento, mas marcado por disparidade de formas e adaptável a um campo de aplicação muito vasto: as comunicações” (BARDIN, 2010, p. 33). A Análise de Conteúdo, ao se voltar a diferentes formatos de mensagens (entrevistas, discursos políticos etc.), permitiu que se adaptassem os objetos de coleta e análise deste trabalho a ela: artigos, disciplinas e projetos de pesquisa.

Bardin (2010) divide o procedimento da Análise de Conteúdo nas seguintes etapas: préanálise, exploração do material e tratamento dos resultados obtidos e interpretação. A préanálise é a coleta dos dados propriamente dita. O primeiro passo foi criar um documento no software Microsoft Excel, incluindo 25 planilhas destinadas aos 25 Programas de PósGraduação em Ciência da Informação no Brasil existentes à época ${ }^{6}$ da coleta.

Todas as planilhas receberam grandes colunas chamadas de "dimensão-ensino", “dimensão-pesquisa" e "dimensão-produção", organizadas a partir dos dados a serem coletados, como mostra a imagem abaixo (exemplificada com um Programa real).

Figura 1 - Exemplo das dimensões "ensino", "pesquisa" e "produção"

\begin{tabular}{|c|c|c|c|c|c|c|c|c|c|c|c|}
\hline A & A & B. & c & D & E & F & G & H & 1 & J & $\mathrm{x}$ \\
\hline 1 & \multicolumn{11}{|c|}{ PROGRAMA DE PÓS-GRADUAÇĀO EM MEMÓRIA E ACERVOS - FUNDAÇĀO CASA DE RUI BARBOSA } \\
\hline 2 & & & & & & & & & & & \\
\hline 3 & \multicolumn{2}{|c|}{ Dimensäo-ensino } & & \multicolumn{3}{|c|}{ Dimensão-pesquisa } & & \multicolumn{3}{|c|}{ Dimensảo-produçăo } & \\
\hline 4 & $\begin{array}{l}\text { Titulos das } \\
\text { disciplinas }\end{array}$ & $\begin{array}{l}\text { Tópicos } \\
\text { atingidos }\end{array}$ & & Docentes & $\begin{array}{c}\text { Tilulos dos } \\
\text { projetos de } \\
\text { pesquisa }\end{array}$ & $\begin{array}{l}\text { Tópicos } \\
\text { atingidos }\end{array}$ & & Docentes & $\begin{array}{c}\text { Titulos dos } \\
\text { artigos }\end{array}$ & $\begin{array}{c}\text { Topicos } \\
\text { atingidos }\end{array}$ & \\
\hline 5 & & & & & & & & & & & \\
\hline 6 & & & & & & & & & & & \\
\hline
\end{tabular}

Fonte: elaborada pelo autor.

A saber, as dimensões se referem aos próprios objetos de análise que foram coletados: artigos, disciplinas e projetos de pesquisa. Ademais, no momento adequado de se fazer a observação, as dimensões foram convertidas em indicadores. É importante notar que este corpus compreende dados entre 2009 e 2018, totalizando 10 anos de recorte temporal.

Ainda na pré-análise, é preciso registrar que, antes de realizar a coleta, buscou-se compreender a Ética da Informação por meio dos seus tópicos de interesse. A compreensão da área foi realizada mediante um levantamento em duas listas diferentes (trabalhadas no software Word, em dois documentos à parte do texto do artigo), dos tópicos de interesse. O texto pivotal foi The Handbook of Information and Computer Ethics, de 2008, de Kenneth E. Himma e Herman Tavani, embora não se tenha aberto mão de outras autoridades em Ética da Informação.

\footnotetext{
${ }^{6}$ Data da coleta: 01 nov. 2018. A coleta foi realizada na Plataforma Sucupira.
} 
$\mathrm{Na}$ primeira lista foram colocados, em formato de quadros, os tópicos com suas definições ou descrições. Esta lista foi criada para servir de alicerce inicial sobre o que se desenha como busca em termos de assuntos/tópicos nos artigos, disciplinas e projetos de pesquisa que estariam caracterizando a Ética da Informação. A segunda lista foi criada durante a própria coleta, visto que a primeira não foi exaustiva e foi preciso controlar o que seria coletado, isto é, tudo o que foi coletado precisou corresponder aos tópicos das listas - bem como suas definições, caso o material em potencial a ser coletado fosse, de alguma maneira, ambíguo.

De importante para se destacar ainda na pré-análise, segundo o que observa a Análise de Conteúdo, criou-se indicadores e um índice. Os indicadores são as dimensões citadas, isto é, ensino, pesquisa e produção, e o índice foi nomeado "Índice de atividades acadêmicas brasileiras sobre Ética da Informação". Os indicadores entrarão em evidência quando do momento das Inferências, onde as dimensões serão analisadas sob o título de "indicadores".

A exploração do material, etapa seguinte à pré-análise, trata do início da análise. A título de observação, embora se tenha decidido seguir a ordem das etapas conforme Bardin (2010) explicita, em alguns momentos a análise se deu anteriormente à coleta, uma vez que para se coletar o material que caracterizou Ética da Informação foi preciso identificar o material de interesse para poder coletá-lo. Isso demandou que já se soubesse como fazer a análise, conhecimento adquirido através da codificação. Esta atua como auxiliar à exploração do material. Codificar é "saber a razão por que é que se analisa, e [...] saber como analisar" (BARDIN, 2010, p. 129). Desta feita, definiu-se unidades de registro e de contexto, próprios da Análise de Conteúdo, para identificar o material.

De modo que se pretendeu levantar como estava caracterizada a Ética da Informação em função de seus tópicos de interesse, decidiu-se por utilizar a unidade de registro de "objeto ou referente", a qual trata "de temas-eixo, em redor dos quais o discurso se organiza" (BARDIN, 2010, p. 132). Os projetos, artigos e disciplinas organizam-se segundo os tópicos (temas-eixo) sobre os quais eles tratam.

Quanto às unidades de contexto, assim se apresentam: com relação aos (a) projetos de pesquisa: título e descrição; aos (b) artigos: título, resumo e palavras-chave, e às (c) disciplinas: título, ementa e bibliografia (quando houvesse plano de ensino localizado). Essas unidades, sendo "(superiores às da unidade de registro), são óptimas para que se possa compreender a significação da unidade de registro" (BARDIN, 2010, p. 133), o que justifica suas escolhas. A saber, os projetos e artigos foram buscados nos Currículo Lattes dos docentes, 
e as disciplinas nos sites dos Programas de Pós-Graduação em Ciência da Informação em atividade no período da pesquisa.

À exceção das disciplinas, não se analisou, necessariamente, nos artigos e nos projetos de todos os docentes dos 25 Programas, todas as unidades de contexto citadas. Pelo caráter abrangente da pesquisa (no sentido de que ela não é amostral), primeiramente se leu o título de cada artigo e projeto. Quando neles houvesse indicação de um tópico ou possibilidade de tópico sobre Ética da Informação, passou-se às outras unidades de contexto: descrição nos projetos e resumo e palavras-chave nos artigos. O objetivo de se passar a estas unidades foi o de averiguar se o(s) tópicos(s) em questão estavam contextualizados no viés ético-informacional ${ }^{7}$, e até mesmo para conhecer melhor o artigo ou projeto a fim de tomar, com cautela, o(s) tópico(s) presente(s) no documento.

A etapa seguinte foi a de enumeração. Tratou-se do modo de contagem das unidades de registro. Escolheu-se "frequência", pois foi realizada uma verificação da ocorrência dos tópicos de interesse à EI nos PPGCI no Brasil.

$\mathrm{O}$ tratamento dos resultados obtidos e a interpretação fizeram parte da última etapa. $\mathrm{O}$ tratamento pede que sejam realizados categorização e cálculos estatísticos. Em função de economia, restringiu-se somente à realização de três gráficos (um para cada indicador: ensino, pesquisa e produção) que, ainda assim, "condensam e põem em relevo as informações fornecidas pela análise" (BARDIN, 2010, p. 127).

A interpretação foi realizada com o auxílio do capítulo "Inferências" de Bardin (2010), subsidiando a pesquisa com a indicação dos polos de análise sobre os quais interpretações pudessem ter sido realizadas. Optou-se pelos polos da mensagem (indicador) e o do emissor (docente).

Dada a elaboração do método, desde a coleta do material identificado até a interpretação, parte-se ao que foi encontrado: os resultados.

\section{RESULTADOS}

O quadro abaixo, com a relação dos Programas de Pós-Graduação em Ciência da Informação (PPGCI) e suas respectivas Instituições de Ensino Superior (IES), auxiliará na

\footnotetext{
${ }^{7}$ Destaca-se aqui que não basta somente uma disciplina, artigo ou projeto de pesquisa estar envolvido com um tópico de interesse da Ética da Informação. Existem assuntos que são abordados por mais de um viés. As fake news, por exemplo, além de poderem receber um viés ético de análise, podem também receber um viés social/sociológico. Caso fossem coletados todos os materiais que abordam tópicos sobre os quais a Ética da Informação também se debruça, os materiais acabariam não afirmando quase nada de significativo. De modo que se buscará caracterizar a área científica, buscará pelos tópicos contextualizados no viés ético.
} 
compreensão das seções. A identificação, nestas seções subsequentes, dos Programas, dar-se-á pela sua devida sigla (a da IES). Os quadros subsequentes referem-se à coleta do material:

Quadro 1 - Relação dos Programas de Pós-Graduação por Instituições de Ensino Superior

\begin{tabular}{|c|c|c|}
\hline Programa de Pós-Graduação & Instituição de Ensino Superior & Sigla \\
\hline PPG em Memória e Acervos & Fundação Casa de Rui Barbosa & FCRB \\
\hline PPG em Ciência da Informação & Fundação Universidade Federal de Sergipe & FUFSE \\
\hline PPG em Ciência da Informação & Universidade de Brasília & UNB \\
\hline PPG em Ciência da Informação & Universidade de São Paulo & USP1 \\
\hline PPG em Ciência da Informação & Universidade de São Paulo & USP2 \\
\hline PPG em Ciência da Informação & Universidade do Estado de Santa Catarina & UDESC \\
\hline PPG em Ciência da Informação & Universidade Estadual de Londrina & UEL \\
\hline PPG em Ciência da Informação & $\begin{array}{l}\text { Universidade Estadual Paulista Júlio de Mesquita } \\
\text { Filho }\end{array}$ & UNESP \\
\hline PPG em Ciência da Informação & Universidade Federal da Bahia & UFBA \\
\hline PPG em Ciência da Informação & Universidade Federal da Paraíba & UFPB \\
\hline PPG em Ciência da Informação & Universidade Federal de Minas Gerais & UFMG1 \\
\hline $\begin{array}{l}\text { PPG em Gestão e Organização do } \\
\text { Conhecimento }\end{array}$ & Universidade Federal de Minas Gerais & UFMG2 \\
\hline PPG em Ciência da Informação & Universidade Federal de Pernambuco & UFPE \\
\hline PPG em Ciência da Informação & Universidade Federal de Santa Catarina & UFSC \\
\hline PPG em Ciência da Informação & Universidade Federal de São Carlos & UFSCAR \\
\hline PPG em Biblioteconomia & Universidade Federal do Cariri & UFCA \\
\hline PPG em Ciência da Informação & Universidade Federal do Ceará & UFC \\
\hline PPG em Biblioteconomia & Universidade Federal do Estado do Rio de Janeiro & UNIRIO1 \\
\hline PPG em Gestão de Documentos e Arquivos & Universidade Federal do Estado do Rio de Janeiro & UNIRIO2 \\
\hline PPG em Ciência da Informação & Universidade Federal do Pará & UFPA \\
\hline PPG em Ciência da Informação & Universidade Federal do Rio de Janeiro & UFRJ \\
\hline $\begin{array}{l}\text { PPG em Gestão da Informação e do } \\
\text { Conhecimento }\end{array}$ & Universidade Federal do Rio Grande do Norte & UFRN \\
\hline PPG em Ciência da Informação & Universidade Federal Fluminense & UFF \\
\hline $\begin{array}{l}\text { PPG em Sistemas de Informação e Gestão } \\
\text { do Conhecimento (Mestrado Profissional) }\end{array}$ & Universidade FUMEC & FUMEC1 \\
\hline $\begin{array}{l}\text { PPG em Sistemas de Informação e Gestão } \\
\text { do Conhecimento (Doutorado) }\end{array}$ & Universidade FUMEC & FUMEC2 \\
\hline
\end{tabular}


Quadro 2 - Dados coletados das disciplinas que tratam de Ética da Informação

\begin{tabular}{|l|l|l|}
\hline \multicolumn{1}{|c|}{ Sigla } & \multicolumn{1}{|c|}{ Disciplina } & \multicolumn{1}{c|}{ Tópico atingido } \\
\hline USP1 & Plágio no contexto da integridade científica & Plágio \\
\hline USP2 & Plágio no contexto da integridade científica & Plágio \\
\hline UDESC & Ética na gestão da informação & Propriedade intelectual e ética da pesquisa \\
\hline \multirow{2}{*}{ UEL } & $\begin{array}{l}\text { Tópicos especiais em Ciência da Informação: } \\
\text { políticas de informação e gestão pública }\end{array}$ & Ética da Informação ${ }^{8}$ \\
\hline \multirow{2}{*}{ UNESP } & Aspectos éticos em organização da informação & $\begin{array}{l}\text { Ética da Informação e ética profissional do } \\
\text { bibliotecário }\end{array}$ \\
\hline UFBA & Pesquisa orientada & Ética da pesquisa \\
\hline UFPB & Ética e responsabilidade social & Ética da Informação e ética da pesquisa \\
\hline \multirow{3}{*}{ UFCA } & $\begin{array}{l}\text { Metodologia da pesquisa em Biblioteconomia e } \\
\text { Ciência da Informação }\end{array}$ & Ética da pesquisa \\
\cline { 2 - 3 } & Ética profissional e da informação & $\begin{array}{l}\text { Ética profissional do bibliotecário, direito } \\
\text { autoral, plágio e Ética da Informação }\end{array}$ \\
\cline { 2 - 4 } & Profissional da Informação & Ética profissional do bibliotecário \\
\hline \multirow{2}{*}{ UFC } & $\begin{array}{l}\text { Metodologia da pesquisa científica em Ciência da } \\
\text { Informação }\end{array}$ & Ética da pesquisa \\
\hline \multirow{2}{*}{ UFRJ } & Políticas do conhecimento e regime de informação & Ética da pesquisa \\
\cline { 2 - 4 } & Tópicos em Ética da Informação & $\begin{array}{l}\text { Ética da informação, ética intercultural da } \\
\text { informação e ética da pesquisa }\end{array}$ \\
\cline { 2 - 4 } & Ética e Informação & Ética da informação \\
\hline \multirow{2}{*}{ UFF } & Aspectos éticos e legais da informação & Direito de acesso à informação \\
\cline { 2 - 4 } & Ciência da Informação e Sociedade & Ética da Informação \\
\cline { 2 - 4 } & Comunicação científica em redes eletrônicas & Ética da pesquisa \\
\hline
\end{tabular}

Fonte: elaborado pelos autores.

Quadro 3 - Dados coletados dos projetos de pesquisa que tratam de Ética da Informação

\begin{tabular}{|c|c|c|c|}
\hline Sigla & Projeto de pesquisa e ano & Docente & Tópico atingido \\
\hline USP1 & $\begin{array}{l}\text { Percepções dos alunos pós-graduandos da USP } \\
\text { sobre a ocorrência de plágio em trabalhos } \\
\text { acadêmicos, } 2012-2014\end{array}$ & $\begin{array}{l}\text { Sueli Mara Soares Pinto } \\
\text { Ferreira }\end{array}$ & Plágio \\
\hline UNESP & $\begin{array}{l}\text { Uso ético y legal de la información digital: } \\
\text { análisis del papel de las bibliotecas en el } \\
\text { asesoramiento y formación de la comunidad } \\
\text { universitaria, } 2012-2014\end{array}$ & $\begin{array}{l}\text { José Augusto Chaves } \\
\text { Guimarães }\end{array}$ & $\begin{array}{l}\text { Ética e } \\
\text { informação na era } \\
\text { digital }\end{array}$ \\
\hline \multirow[t]{2}{*}{ UFPE } & $\begin{array}{l}\text { Aspectos éticos na representação do } \\
\text { conhecimento: uso do metafiltro no controle } \\
\text { terminológico de metáforas no domínio da } \\
\text { homossexualidade, } 2014 \text { - atual }\end{array}$ & \multirow[t]{2}{*}{ Fábio Assis Pinho } & \multirow[t]{2}{*}{$\begin{array}{l}\text { Ética profissional } \\
\text { do bibliotecário }\end{array}$} \\
\hline & $\begin{array}{l}\text { Ética no Tratamento Temático da Informação, } \\
2010 \text { - atual }\end{array}$ & & \\
\hline UFCA & $\begin{array}{l}\text { Múltiplas interlocuções crítico-criativas no } \\
\text { âmbito dos fundamentos filosóficos da } \\
\text { informação: perspectivas para construção e } \\
\text { aplicação conceitual, } 2017 \text { - atual }\end{array}$ & $\begin{array}{l}\text { Jonathas Luiz Carvalho } \\
\text { Silva }\end{array}$ & $\begin{array}{l}\text { Ética da } \\
\text { Informação }\end{array}$ \\
\hline $\begin{array}{l}\text { UNIRIO } \\
2\end{array}$ & $\begin{array}{l}\text { Integridade da Pesquisa, ética da ciência e da } \\
\text { informação, } 2014 \text { - atual }\end{array}$ & $\begin{array}{l}\text { Alexandre de Souza } \\
\text { Costa }\end{array}$ & $\begin{array}{l}\text { Ética da pesquisa } \\
\text { e Ética da } \\
\text { Informação }\end{array}$ \\
\hline \multirow[t]{2}{*}{ UFRJ } & $\begin{array}{l}\text { Ética, Política e Epistemologia: interfaces da } \\
\text { informação, } 2013 \text { - atual }\end{array}$ & $\begin{array}{l}\text { Marco André Feldman } \\
\text { Schneider }\end{array}$ & $\begin{array}{l}\text { Ética da } \\
\text { Informação }\end{array}$ \\
\hline & $\begin{array}{l}\text { Integridade da pesquisa, ética da ciência e da } \\
\text { informação, } 2014 \text { - atual }\end{array}$ & $\begin{array}{l}\text { Maria Nélida Gonzalez } \\
\text { de Gómez }\end{array}$ & $\begin{array}{l}\text { Ética da pesquisa } \\
\text { e Ética da } \\
\text { Informação }\end{array}$ \\
\hline
\end{tabular}

\footnotetext{
${ }^{8}$ Embora todos os tópicos tratem de Ética da Informação, o tópico que recebeu este nome se define pela área científica sendo tratada de maneira geral ou introdutória, sem que na definição se adentre nos tópicos de interesse da área (plágio, direito de acesso à informação, etc.).
} 


\begin{tabular}{|l|l|l|l|}
\hline UFF & $\begin{array}{l}\text { Integridade da Pesquisa, ética da ciência e da } \\
\text { informação, 2014 - atual }\end{array}$ & $\begin{array}{l}\text { Maria Nélida Gonzalez } \\
\text { de Gómez }\end{array}$ & $\begin{array}{l}\text { Ética da pesquisa } \\
\text { e Ética da } \\
\text { Informação }\end{array}$ \\
\hline
\end{tabular}

Fonte: elaborado pelos autores.

Quadro 4 - Dados coletados dos artigos que tratam de Ética da Informação

\begin{tabular}{|c|c|c|c|}
\hline Sigla & Artigo e ano & Docente & Tópico atingido \\
\hline \multirow[t]{2}{*}{ USP1 } & Ethics of Information in the Digital Age, 2017 & \multirow[t]{2}{*}{$\begin{array}{l}\text { Francisco Carlos } \\
\text { Paletta }\end{array}$} & $\begin{array}{l}\text { Ética e } \\
\text { Informação na era } \\
\text { digital }\end{array}$ \\
\hline & $\begin{array}{l}\text { Relatório do III Simpósio Brasileiro de Ética da } \\
\text { Informação: ética da informação na web, } 2017\end{array}$ & & $\begin{array}{l}\text { Ética da } \\
\text { Informação na } \\
\text { Web }\end{array}$ \\
\hline \multirow[t]{4}{*}{ UDESC } & $\begin{array}{l}\text { Preceitos éticos no comportamento do bibliotecário } \\
\text { empreendedor, } 2017\end{array}$ & $\begin{array}{l}\text { Daniela Fernanda } \\
\text { Assis de Oliveira } \\
\text { Spudeit }\end{array}$ & $\begin{array}{l}\text { Ética profissional } \\
\text { do bibliotecário }\end{array}$ \\
\hline & $\begin{array}{l}\text { Ética profissional do bibliotecário atuante no } \\
\text { segmento empresarial de Santa Catarina, } 2011\end{array}$ & $\begin{array}{l}\text { Daniella Camara } \\
\text { Pizzarro }\end{array}$ & $\begin{array}{l}\text { Ética profissional } \\
\text { do bibliotecário }\end{array}$ \\
\hline & $\begin{array}{l}\text { A ética profissional do bibliotecário frente ao } \\
\text { comércio de trabalhos acadêmicos, } 2016\end{array}$ & \multirow[t]{2}{*}{$\begin{array}{l}\text { José Cláudio Morelli } \\
\text { Matos }\end{array}$} & $\begin{array}{l}\text { Ética profissional } \\
\text { do bibliotecário }\end{array}$ \\
\hline & $\begin{array}{l}\text { Zumbificação da informação: a desinformação e o } \\
\text { caos informacional, } 2017\end{array}$ & & Desinformação \\
\hline \multirow[t]{15}{*}{ UNESP } & $\begin{array}{l}\text { Library classifications criticisms: universality, } \\
\text { poststructuralism and ethics, } 2013\end{array}$ & $\begin{array}{l}\text { Daniel Martínez- } \\
\text { Ávila }\end{array}$ & $\begin{array}{l}\text { Ética profissional } \\
\text { do bibliotecário }\end{array}$ \\
\hline & $\begin{array}{l}\text { Uso ético da informação e combate ao plágio: olhares } \\
\text { para as bibliotecas universitárias brasileiras, } 2016\end{array}$ & \multirow[t]{2}{*}{$\begin{array}{l}\text { Helen de Castro Silva } \\
\text { Casarin }\end{array}$} & Plágio \\
\hline & $\begin{array}{l}\text { Aspectos éticos e legais da competência } \\
\text { informacional e a formação do bibliotecário: um } \\
\text { estudo com graduandos de biblioteconomia da região } \\
\text { sudeste, } 2011\end{array}$ & & $\begin{array}{l}\text { Ética profissional } \\
\text { do bibliotecário }\end{array}$ \\
\hline & $\begin{array}{l}\text { Análise do discurso literário para a representação da } \\
\text { informação: viés ético, } 2017\end{array}$ & $\begin{array}{l}\text { João Batista Ernesto } \\
\text { de Moraes }\end{array}$ & $\begin{array}{l}\text { Ética profissional } \\
\text { do bibliotecário }\end{array}$ \\
\hline & $\begin{array}{l}\text { Aspectos éticos da coautoria em publicações } \\
\text { científicas, } 2018\end{array}$ & \multirow{10}{*}{$\begin{array}{l}\text { José Augusto Chaves } \\
\text { Guimarães }\end{array}$} & \multirow{10}{*}{$\begin{array}{l}\text { Ética profissional } \\
\text { do bibliotecário }\end{array}$} \\
\hline & $\begin{array}{l}\text { Problemas relacionados a Biases em Sistemas de } \\
\text { Organização do Conhecimento: perspectivas para a } \\
\text { Representação de Assunto, } 2018\end{array}$ & & \\
\hline & $\begin{array}{l}\text { Theoretical dialogs about ethical issues in knowledge } \\
\text { organization: García Gutiérrez, Hudon, Beghtol, and } \\
\text { Olson, } 2016\end{array}$ & & \\
\hline & $\begin{array}{l}\text { A exaustividade e a especificidade como valores } \\
\text { éticos na indexação: uma análise baseada na literatura } \\
\text { disponibilizada em Portugal, } 2016\end{array}$ & & \\
\hline & $\begin{array}{l}\text { Valores éticos na organização e representação do } \\
\text { conhecimento, } 2015\end{array}$ & & \\
\hline & $\begin{array}{l}\text { The ethics of knowledge organization and } \\
\text { representation from a Bakhtinian perspective, } 2015\end{array}$ & & \\
\hline & $\begin{array}{l}\text { Library Classifications Criticism: Universality, } \\
\text { Poststructuralism and Ethics, } 2013\end{array}$ & & \\
\hline & $\begin{array}{l}\text { Male homosexuality in Brazilian indexing languages: } \\
\text { some ethical questions, } 2012\end{array}$ & & \\
\hline & $\begin{array}{l}\text { Problemas éticos em representação do conhecimento: } \\
\text { uma abordagem teórica, } 2011\end{array}$ & & \\
\hline & $\begin{array}{l}\text { Ética en organización y representación del } \\
\text { conocimiento: aspectos teóricos, } 2010\end{array}$ & & \\
\hline & $\begin{array}{l}\text { A exaustividade e a especificidade como valores } \\
\text { éticos no processo de indexação: uma análise baseada } \\
\text { na literatura disponibilizada em Portugal, } 2016\end{array}$ & $\begin{array}{l}\text { Maria da Graça Melo } \\
\text { Simões }\end{array}$ & $\begin{array}{l}\text { Ética profissional } \\
\text { do bibliotecário }\end{array}$ \\
\hline
\end{tabular}




\begin{tabular}{|c|c|c|c|}
\hline & $\begin{array}{l}\text { Aspectos éticos da coautoria em publicações } \\
\text { científicas, } 2018\end{array}$ & $\begin{array}{l}\text { Maria Cláudia } \\
\text { Cabrini Grácio }\end{array}$ & Ética da pesquisa \\
\hline & $\begin{array}{l}\text { Ética informacional: uma abordagem no contexto da } \\
\text { inteligência coletiva, } 2014\end{array}$ & $\begin{array}{l}\text { Plácida Leopoldina } \\
\text { Ventura Amorim da } \\
\text { Costa Santos }\end{array}$ & $\begin{array}{l}\text { Ética intercultural } \\
\text { da Informação }\end{array}$ \\
\hline & $\begin{array}{l}\text { Ação moral e ontologia digital na América Latina: } \\
\text { considerações a partir do pensamento de Rafael } \\
\text { Capurro, } 2015\end{array}$ & $\begin{array}{l}\text { Ricardo César } \\
\text { Gonçalves Sant'Ana }\end{array}$ & Rafael Capurro \\
\hline \multirow[t]{3}{*}{ UFBA } & $\begin{array}{l}\text { Relatório do III Simpósio Brasileiro de Ética da } \\
\text { Informação: ética da informação na web, } 2017\end{array}$ & \multirow[t]{2}{*}{ Isa Maria Freire } & \multirow{2}{*}{$\begin{array}{l}\text { Ética da } \\
\text { Informação na } \\
\text { Web }\end{array}$} \\
\hline & $\begin{array}{l}\text { Reflexões sobre uma ética da informação na } \\
\text { sociedade em rede, } 2010\end{array}$ & & \\
\hline & $\begin{array}{l}\text { O plágio em publicações científicas e a percepção } \\
\text { dos graduandos em Biblioteconomia e Documentação } \\
\text { do Instituto de Ciência da Informação da } \\
\text { Universidade Federal da Bahia, } 2017\end{array}$ & $\begin{array}{l}\text { José Carlos Sales dos } \\
\text { Santos }\end{array}$ & Plágio \\
\hline \multirow[t]{5}{*}{ UFPB } & $\begin{array}{l}\text { Ética profissional na formação do bibliotecário: o } \\
\text { Curso de Biblioteconomia da UFC no Cariri, } 2011\end{array}$ & Gracy Kelli Martins & $\begin{array}{l}\text { Ética profissional } \\
\text { do bibliotecário }\end{array}$ \\
\hline & $\begin{array}{l}\text { Relatório do III Simpósio Brasileiro de Ética da } \\
\text { Informação: ética da informação na web, } 2017\end{array}$ & $\begin{array}{l}\text { Gustavo Henrique } \\
\text { Araújo Freire }\end{array}$ & $\begin{array}{l}\text { Ética da } \\
\text { Informação na } \\
\text { Web }\end{array}$ \\
\hline & $\begin{array}{l}\text { Relatório do III Simpósio Brasileiro de Ética da } \\
\text { Informação: ética da informação na web, } 2017\end{array}$ & \multirow[t]{2}{*}{ Isa Maria Freire } & \multirow{2}{*}{$\begin{array}{l}\text { Ética da } \\
\text { Informação na } \\
\text { Web }\end{array}$} \\
\hline & $\begin{array}{l}\text { Reflexões sobre uma ética da informação na } \\
\text { sociedade em rede, } 2010\end{array}$ & & \\
\hline & $\begin{array}{l}\text { Ética profissional na formação do bibliotecário: o } \\
\text { Curso de Biblioteconomia da UFC no Cariri, } 2011\end{array}$ & $\begin{array}{l}\text { Maria Cleide } \\
\text { Rodrigues Bernardino }\end{array}$ & $\begin{array}{l}\text { Ética profissional } \\
\text { do bibliotecário }\end{array}$ \\
\hline \multirow[t]{2}{*}{ UFMG2 } & $\begin{array}{l}\text { As questões éticas da democratização da informação, } \\
2013\end{array}$ & $\begin{array}{l}\text { Dalgiza Andrade } \\
\text { Oliveira }\end{array}$ & $\begin{array}{l}\text { Direito de acesso } \\
\text { à informação }\end{array}$ \\
\hline & $\begin{array}{l}\text { A exaustividade e a especificidade como valores } \\
\text { éticos no processo de indexação: uma análise baseada } \\
\text { na literatura disponibilizada em Portugal, } 2016\end{array}$ & $\begin{array}{l}\text { Maria da Graça de } \\
\text { Melo Simões }\end{array}$ & $\begin{array}{l}\text { Ética profissional } \\
\text { do bibliotecário }\end{array}$ \\
\hline \multirow[t]{3}{*}{ UFPE } & $\begin{array}{l}\text { Conexão e distanciamento conceitual entre filosofia, } \\
\text { ética e direito da informação, } 2018\end{array}$ & $\begin{array}{l}\text { Diego Andres } \\
\text { Salcedo }\end{array}$ & $\begin{array}{l}\text { Direito de acesso } \\
\text { à informação }\end{array}$ \\
\hline & $\begin{array}{l}\text { Theoretical dialogs about ethical issues in } \\
\text { Knowledge Organization: García Gutiérrez, Hudon, } \\
\text { Beghtol, and Olson, } 2016\end{array}$ & \multirow[t]{2}{*}{ Fábio Assis Pinho } & \multirow[t]{2}{*}{$\begin{array}{l}\text { Ética profissional } \\
\text { do bibliotecário }\end{array}$} \\
\hline & $\begin{array}{l}\text { Male Homosexuality in Brazilian Indexing } \\
\text { Languages: some ethical questions, } 2012\end{array}$ & & \\
\hline UFSC & $\begin{array}{l}\text { La competencia informacional y derechos de autor en } \\
\text { las bibliotecas de instituciones de educación superior } \\
\text { de Brasil, } 2015\end{array}$ & $\begin{array}{l}\text { Enrique Muriel } \\
\text { Torrado }\end{array}$ & Direito autoral \\
\hline \multirow[t]{4}{*}{ UFCA } & \multirow{3}{*}{$\begin{array}{l}\text { Ética profissional na formação do bibliotecário: o } \\
\text { Curso de Biblioteconomia da UFC no Cariri, } 2011\end{array}$} & Ariluci Goes Elliott & \multirow{3}{*}{$\begin{array}{l}\text { Ética profissional } \\
\text { do bibliotecário }\end{array}$} \\
\hline & & Gracy Kelli Martins & \\
\hline & & $\begin{array}{l}\text { Maria Cleide } \\
\text { Rodrigues Bernardino }\end{array}$ & \\
\hline & $\begin{array}{l}\text { A tríade identidade, ética e informação na } \\
\text { Biblioteconomia brasileira: análise sobre o Código de } \\
\text { Ética do Bibliotecário, } 2010\end{array}$ & $\begin{array}{l}\text { Jonathas Luiz } \\
\text { Carvalho Silva }\end{array}$ & $\begin{array}{l}\text { Ética profissional } \\
\text { do bibliotecário }\end{array}$ \\
\hline UFC & $\begin{array}{l}\text { Ética profissional, deontologia e sindicalismo na } \\
\text { Biblioteconomia brasileira: múltiplas perspectivas } \\
\text { históricas de atuação, } 2018\end{array}$ & $\begin{array}{l}\text { Jefferson Veras } \\
\text { Nunes }\end{array}$ & $\begin{array}{l}\text { Ética profissional } \\
\text { do bibliotecário }\end{array}$ \\
\hline \multirow[t]{2}{*}{ UNIRIO1 } & $\begin{array}{l}\text { Privacidade, ética e informação: uma reflexão } \\
\text { filosófica sobre os dilemas no contexto das redes } \\
\text { sociais, } 2017\end{array}$ & $\begin{array}{l}\text { Gustavo Silva } \\
\text { Saldanha }\end{array}$ & $\begin{array}{l}\text { Privacidade } \\
\text { informacional }\end{array}$ \\
\hline & Saúde, ética e integridade da pesquisa no Brasil, 2016 & $\begin{array}{l}\text { Lidiane dos Santos } \\
\text { Carvalho }\end{array}$ & Ética da pesquisa \\
\hline UFPA, & $\begin{array}{l}\text { Ação moral e ontologia digital na América Latina: } \\
\text { considerações a partir do pensamento de Rafael }\end{array}$ & $\begin{array}{l}\text { Cristian Berrío } \\
\text { Zapata }\end{array}$ & Rafael Capurro \\
\hline
\end{tabular}




\begin{tabular}{|l|l|l|l|}
\hline & Capurro, 2015 & & \\
\hline UFRJ & $\begin{array}{l}\text { Privacidade, ética e informação: uma reflexão } \\
\text { filosófica sobre os dilemas no contexto das redes } \\
\text { sociais, 2017 }\end{array}$ & $\begin{array}{l}\text { Gustavo Silva } \\
\text { Saldanha }\end{array}$ & $\begin{array}{l}\text { Privacidade } \\
\text { informacional }\end{array}$ \\
\cline { 2 - 4 } & $\begin{array}{l}\text { Discussing plagiarism in Latin American Science. } \\
\text { Brazilian researchers begin to address an ethical } \\
\text { issue, 2009 }\end{array}$ & Jacqueline Leta & Plágio \\
\cline { 2 - 4 } & Marx, ética e a Ciência da Informação, 2018 & $\begin{array}{l}\text { Ricardo Medeiros } \\
\text { Pimenta }\end{array}$ & $\begin{array}{l}\text { Ética da } \\
\text { Informação }\end{array}$ \\
\hline
\end{tabular}

Fonte: elaborado pelos autores.

Os gráficos abaixo, isto é, o tratamento dos resultados, referem-se aos indicadores de ensino, pesquisa e produção. A quantidade se refere ao número de vezes que em artigos, disciplinas e projetos de pesquisa foram encontrados tópicos de interesse da Ética da Informação, independentemente do fato de, por ventura, estes artigos, disciplinas e projetos tivessem feito parte de mais de um Programa de Pós-Graduação dentre os 25 analisados:

Gráfico 1 - Frequência de ocorrência de tópicos do indicador de ensino

\section{Frequência de ocorrência de tópicos do indicador de ensino}

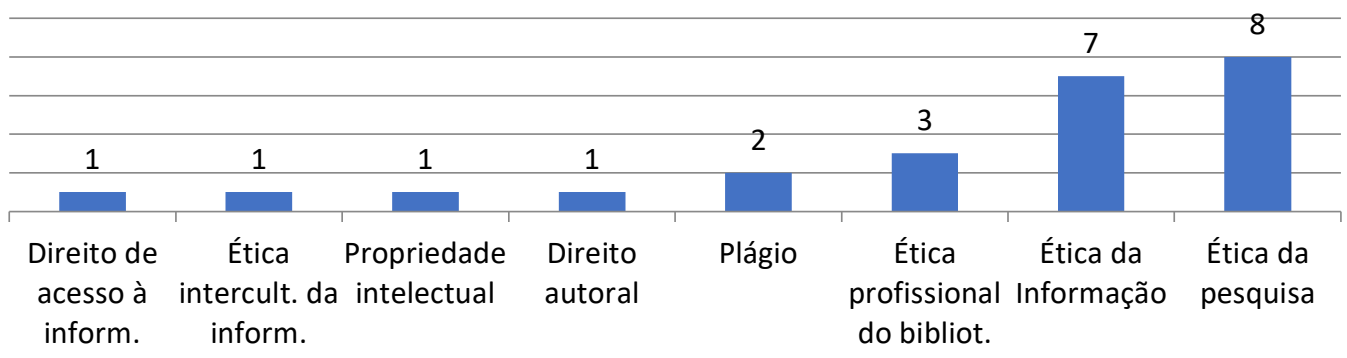

Fonte: elaborado pelos autores.

Gráfico 2 - Frequência de ocorrência de tópicos do indicador de pesquisa

\section{Frequência de ocorrência de tópicos do indicador de pesquisa}

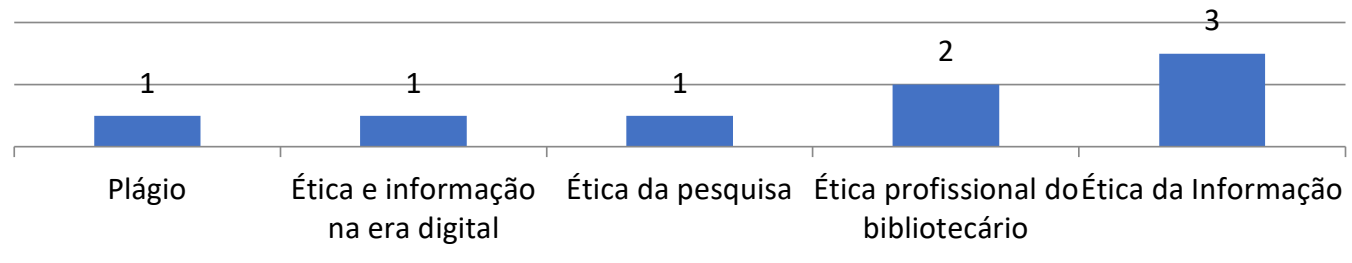

Fonte: elaborado pelos autores. 
Gráfico 3 - Frequência de ocorrência de tópicos do indicador de produção

\section{Frequência de ocorrência de tópicos do indicador de produção}

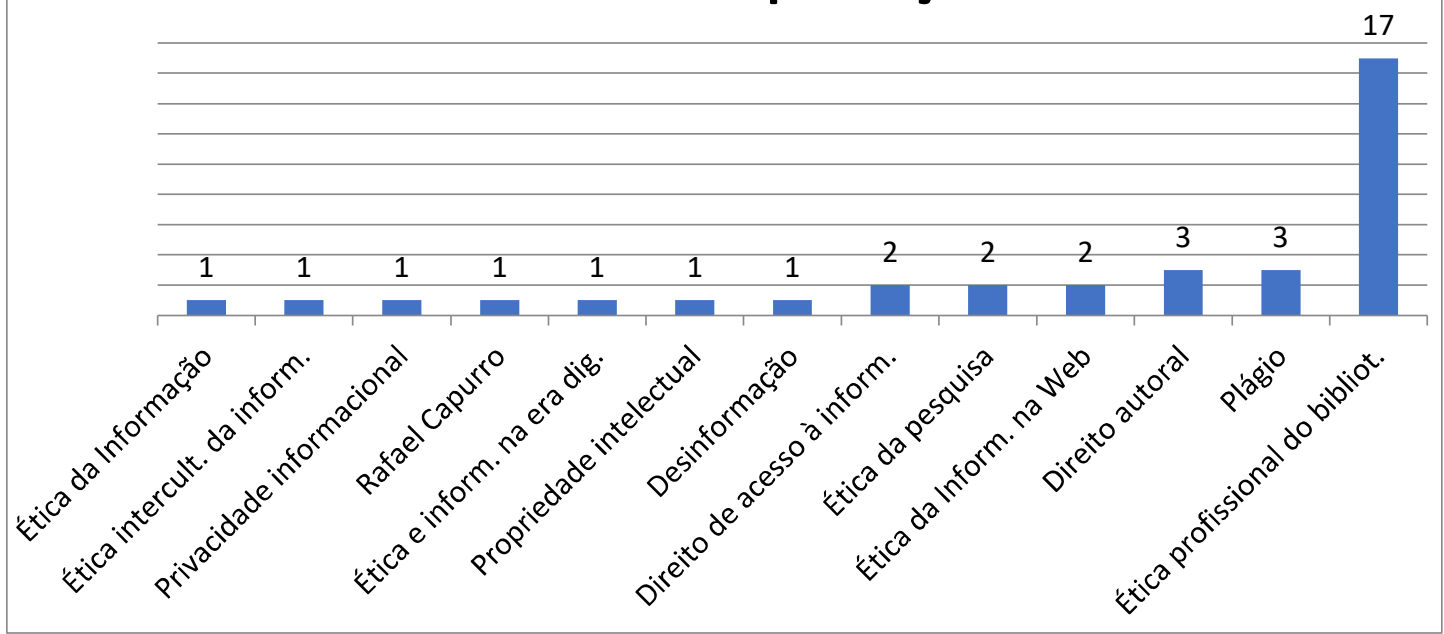

Fonte: elaborado pelos autores

Chama atenção, ao fazer uma leitura dos gráficos, a quantidade de vezes em que o tópico de ética profissional do bibliotecário ocorreu, com ênfase no indicador de produção. Houve, ainda, diversos assuntos encontrados apenas uma vez (14, somando-se os três gráficos).

\section{COMPOSIÇÃO DA ÉTICA DA INFORMAÇÃO NOS PROGRAMAS DE PÓS- GRADUAÇÃO EM CIÊNCIA DA INFORMAÇÃO NO BRASIL: INFERÊNCIAS}

Como se afirmou no método, a inferência se deu sobre dois polos de análise: a mensagem (os indicadores) e o emissor. Quanto ao primeiro polo, pode-se começar apontando em que aspectos a Ética da Informação (EI) encontra-se mais ou menos abordada, e a partir daí tecer relações entre os indicadores.

Constatou-se que a frequência de ocorrência de tópicos da área científica nos indicadores de pesquisa, ensino e produção se deu, respectivamente, pelos seguintes números: 8, 24 e 36. Embora se tenha notado a disparidade de frequência de ocorrência entre ensino e produção, limitou-se aos indicadores de pesquisa e produção porque ambos concentram parte significativa de ocorrência por meio do tópico "ética profissional do bibliotecário".

Pode-se começar mencionando que o maior contribuinte às 36 ocorrências em artigos foi José Augusto Chaves Guimarães: em 9 artigos encontrou-se o tópico citado. No entanto, mesmo diante desta quantidade, reparou-se numa disparidade, pois não se localizou nenhum projeto de pesquisa sobre o mesmo tópico. Seu único projeto diz respeito ao tópico "ética e 
informação na era digital". ${ }^{9}$ Visto que a produção acadêmica surge em decorrência de pesquisa, esperava-se que a disparidade fosse menor.

De fato, verificando a análise realizada, constatou-se que nos gráficos dos indicadores de pesquisa e produção encontrou-se 2 projetos e 17 artigos sobre ética profissional do bibliotecário. Um programa no qual se poderia ter encontrado um projeto sobre o tópico em questão é o da Universidade do Estado de Santa Catarina: nele foi onde se localizou a maior diversidade de artigos sobre o tópico nos últimos 10 anos: 3. Seus autores são: José Cláudio Morelli Matos, que "tem experiência na área de Teoria do Conhecimento e Ética", ${ }^{10}$ embora seus projetos se voltem à filosofia de Dewey (como também consta em seu Lattes); Daniela Fernanda Spudeit, a qual tem como área de interesse a "formação em biblioteconomia"11 (seu artigo se chama Preceitos éticos no comportamento do bibliotecário empreendedor). O último destes professores, Daniela Camara, possui um projeto de pesquisa voltado à ética profissional do bibliotecário, mas o mesmo não se adequou à definição do tópico elaborada em documento à parte. ${ }^{12}$

Encontrou-se "coerência" entre os indicadores de pesquisa e produção no docente Fábio Assis Pinho, por exemplo. O mesmo possui dois projetos de pesquisa e dois artigos já realizados sobre ética profissional do bibliotecário, para ficar no mesmo tópico.

Finalizada a discussão da inferência sobre os indicadores, pode-se interpretar resultados obtidos segundo o polo de análise do emissor. Pretende-se tratar da participação de duas pesquisadoras em função de dois tópicos: Ética da Informação e Ética da Informação na Web.

É interessante notar, restringindo-se, por ora, ao tópico Ética da Informação na Web, uma docente em especial: Isa Maria Freire. A mesma tem uma presença significativa em discussões ético-informacionais, pois foi coautora do Relatório do III Simpósio Brasileiro de Ética da Informação: ética da informação na web, de 2017, e foi autora de Reflexões sobre uma ética da informação na sociedade em rede, de 2011. Mais: transpassando o gênero dos artigos (do próprio método utilizado), para citar sua relevância no tópico em questão, ela ainda

\footnotetext{
${ }^{9} \mathrm{O}$ tópico originou-se do artigo de Rafael Capurro chamado Ethics and Information in the Digital Age (a tradução livre originou o nome do tópico). O mesmo restringe-se a questionamentos éticos acerca da profissão de bibliotecário na era digital, como de que forma "[...] pode ser garantido um direito de acesso ao conhecimento? [...] Que tipos de serviços elas [bibliotecas digitais] podem oferecer?” (CAPURRO, 2001, p. 3, tradução nossa). Estas questões são diferentes daquelas pensadas sobre o tópico "ética profissional do bibliotecário", que volta à "[...] seleção e organização de informação, que carregam problemas de viés, neutralidade e direitos de acesso à informação para crianças" (MATHIESEN; FALLIS, 2008, p. 222, tradução nossa).

${ }^{10} \mathrm{http}$ ://buscatextual.cnpq.br/buscatextual/visualizacv.do?id=K4167109J4. Data da coleta: 23/11/2018

${ }^{11} \mathrm{http} / / /$ buscatextual.cnpq.br/buscatextual/visualizacv.do?id=K4256260D5. Data da coleta: 23/11/2018.

${ }^{12} \mathrm{O}$ nome do projeto de pesquisa da docente é $O$ processo educacional do bibliotecário na graduação e sua formação ético-profissional. Quanto à definição do tópico elaborada, o projeto não trata da seleção da informação, da organização da informação ou ainda do Código de Ética Profissional do Bibliotecário.
}

LOGEION: Filosofia da informação, Rio de Janeiro, v. 6 n. 1, p.27-43, set.2019/fev. 2020 
contribuiu com um capítulo denominado A consciência possível para uma ética da informação na sociedade em rede, do livro Ética da Informação: conceitos, abordagens e aplicações, de 2010, de Gustavo Henrique Freire.

Finalmente, chega-se à interpretar a participação de Maria Nélida González de Gómez, um dos principais nomes da Ética da Informação brasileira ${ }^{13}$. Nos gêneros escolhidos (disciplina, projeto de pesquisa e artigo) não se pôde conhecer quase nada do trabalho da pesquisadora sobre a área científica. Embora ela atue sobre um projeto de pesquisa (Integridade da pesquisa, ética da ciência e da informação, de 2014) sobre o qual se constatou o tópico "Ética da Informação", não se encontrou artigos de sua autoria ou ainda disciplinas ministradas.

A pesquisadora, no entanto, também transpassa em contribuição à área científica, pois é coautora do livro Ética da Informação: perspectivas e desafios, de 2017, relevante ao tópico “Ética da Informação". ${ }^{14}$ Então, cada uma destas, e demais pesquisadores de EI que não receberam seu espaço aqui, puderam ter contribuído de outras maneiras. A própria Maria Nélida González de Gómez escreveu um capítulo do livro citado.

\section{ALGUMAS CONSIDERAÇÕES FINAIS}

Finaliza-se este trabalho apontando que outras abordagens podem ser consideradas para trabalhos futuros, sendo interessante, por exemplo, aplicar uma outra análise da Ética da Informação (EI) na Pós-Graduação brasileira em Ciência da Informação, mas com um método diferente. Uma aposta seria fazer uma amostra do total de Programas e, com um número reduzido, coletar não apenas disciplinas, projetos de pesquisa e artigos, mas também livros e capítulos de livros, por exemplo.

Recebeu grande destaque o caso de Maria Nélida González de Gómez quando da inferência, pois enquanto não foi possível encontrar nenhum artigo de sua autoria ou disciplina ministrada, ela ainda assim detém relevante importância à EI brasileira. Portanto, um trabalho mais aprofundado e menos abrangente poderia mostrar atividades acadêmicas que passaram despercebidas neste trabalho (pela limitação de se trabalhar com artigos, projetos e disciplinas), e assim seria tão mais evidente a presença da Ética da Informação nos Programas no país.

As observações que podem ser realizadas sobre as inferências dizem respeito à questão da disparidade entre os indicadores de pesquisa e produção. Até que ponto projetos de pesquisa

\footnotetext{
${ }^{13}$ A autora circula por diversas áreas da Ciência da Informação, sendo nome relevante da área. Como o foco do trabalho está restrito à Ética da Informação, fazemos menção à esta área.

${ }^{14}$ Tópico destinado a tratar a área científica de modo geral ou introdutório.
} 
e artigos precisam andar juntos é um questionamento (retomando o caso de José Augusto Chaves Guimarães e Fábio Assis Pinho, em que aquele escreveu vários artigos sobre ética profissional e um só projeto, nos últimos 10 anos, que não tinha relação direta com os mesmos, ${ }^{15}$ e em que Fábio Pinho manteve uma "coerência" entre pesquisa e produção).

Por fim, tomou-se dois tópicos para tratar da relevância da Ética da Informação na atualidade: plágio e desinformação. O primeiro deles, dentro da academia, está recebendo cada vez maior destaque, e o outro é, possivelmente, um dos temas mais comentados atualmente no mundo (basta estar a par de como é o fluxo de informações na internet e como a mídia trata o tema no meio virtual).

Portanto, a criação de disciplinas, projetos e/ou artigos sobre tópicos no contexto éticoinformacional, como os dois acima mencionados, é justificável, pois reflete um crescente número de desafios quanto à produção, transmissão e uso de informação na sociedade. Finalmente, é preciso haver uma área a qual valide as três atividades acadêmicas citadas e que sirva para mostrar que existem pesquisadores buscando entender os desafios éticoinformacionais e tentando dar respostas a eles, e a Ética da Informação parece ser esta área.

${ }^{15}$ Que diz respeito ao tópico "Ética e informação na era digital", cuja definição foi baseada nos questionamentos de Capurro acerca do direito de acesso ao conhecimento na era digital: "Como pode ser garantido um direito de acesso ao conhecimento? Criar bibliotecas digitais pode ser uma resposta a esta pergunta, mas como elas se fundem às bibliotecas tradicionais? Que tipos de serviços públicos elas podem oferecer?” (CAPURRO, 2001, p. 3). 


\section{REFERENCIAS}

BARDIN, L. Análise de conteúdo. Edição rev. e actual. Lisboa: Edições 70, 2010.

CAPURRO, R. Ethics and information in the digital age. In: ANNUAL COURSE AND CONFERENCE IN LIBRARIES IN THE DIGITAL AGE, 2001, Dubrovnik (Croácia). Anais [...] Zagreb (Croácia): Universidade de Zagreb, 2001. p. 1-8. Disponível em: http://www.capurro.de/lida2001.pdf. Acesso em: 21 fev. 2019.

FROEHLICH, T. A not-no-brief account of current information ethics: The ethics of ignorance, missing information, misinformation, disinformation and other forms of deception or incompetence. BiD: textos universitaris de biblioteconomia i documentació, Barcelona, n. 39, desembre, 2017. Disponível em: http://bid.ub.edu/en/39/froehlich.htm. Acesso em: 21 fev. 2019.

GERHARDT, T. E.; SILVEIRA, D. T. (Org.). Métodos de pesquisa. Porto Alegre: Editora da UFRGS, 2009. Disponível em:

http://www.ufrgs.br/cursopgdr/downloadsSerie/derad005.pdf. Acesso em: 21 fev. 2019.

GONZÁLES DE GÓMEZ, M. N.; CIANCONI, R. de B. (Org.) Ética da informação: perspectivas e desafios. Niterói: PPGCI/UFF, 2017. Disponível em:

https://www.researchgate.net/publication/319275884_ETICA_DA_INFORMACAO_perspect ivas_e_desafios. Acesso em: $21 \mathrm{fev} .2019$.

MATHIESEN, K. Towards a political philosophy of information. Library Trends, Baltimore, v. 63, n. 3, p. 427-447, 2015. Issue on exploring philosophies of information. Disponível em: https://papers.ssrn.com/sol3/papers.cfm?abstract_id=2944833. Acesso em: 21 fev. 2019.

MATHIESEN, K.; FALLIS, D. Information Ethics and the Library Profession. In: HIMMA, K. E.; TAVANI, H. T. (Ed.). The handbook of information and computer Eehics. New Jersey: John Wiley \& Sons, 2008, p. 221-244.

RUDIO, F. V. Introdução ao projeto de pesquisa científica. Petrópolis: Vozes, 1978. 